\title{
History and Philosophy of Science Can Improve Problem-Solving
}

\section{Ricardo Lopes Coelho ${ }^{1}$}

Secção Autónoma de História e Filosofia das Ciências, Faculdade de Ciências da Universidade de Lisboa e Centro Interuniversitário de História das Ciências e da Tecnologia

Campo Grande C4.3.22, 1749-016 Lisboa, Portugal

E-mail: rlc@fc.ul.pt

There has been much research on students' misunderstandings of force. Some physicists have pointed out, however, that we do not know what force is. The most common definition of force in textbooks - force is the cause of acceleration - has been criticized for more than two centuries (d'Alembert, Carnot, Kirchhoff, Mach, Hertz, Poincaré, among others). By means of the simple Atwood machine problem, it will be shown that the concept of force as cause of acceleration is not tenable (Poggendorff 1854, P. and N. Graneau 2006, Coelho 2013).

Frontiers of Fundamental Physics 14

FFP14

15-18 July 2014

Aix Marseille University (AMU) Saint-Charles Campus, Marseille

${ }^{1}$ Speaker 


\section{Introduction}

Some projects have been developed in order to improve science teaching through History of Science. The most famous one was the Harvard Project Physics and the last one was perhaps the European HIPST project, in which I participated. The efforts made in the course of time have changed the role of the History and Philosophy of Science in science teaching. The aim is not to use HS to adorn physics teaching but rather to understand conceptual problems which have a historical origin and to improve problem-solving strategies. This will be exemplified next by means of the Atwood machine problem.

\section{On the Common Problem-Solving Strategy of the Atwood Machine}

In the common problem-solving strategy of the Atwood machine (hereafter abbreviated as Atm), the equation $F=m a$ is applied to both bodies on the machine (fig. 1). Forces weight $\mathrm{W}_{2}$ and tension $\mathrm{T}_{2}$ act on body 2 and cause acceleration $\mathrm{a}_{2}$. As this body accelerates upwards, $\mathrm{T}_{2}$ is greater than $\mathrm{W}_{2}$ :

$$
T_{2}-W_{2}=m_{2} a_{2} .
$$

The same reasoning holds mutatis mutandis for body 3 , which moves downwards,

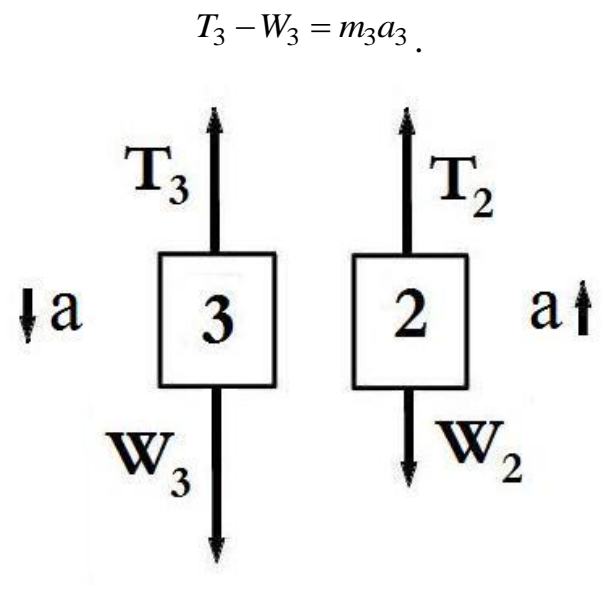

Figure 1: Free-body Diagram.

It is drawn from the problem that

$$
a_{3}=-a_{2}
$$

and added that the pulley and string are massless and the pulley is frictionless. Due to this ideal condition,

$$
\mathrm{T}_{2}=\mathrm{T}_{3},
$$

the number of unknowns in the equations is reduced and the problem becomes solvable. Eliminating the tensions in the equations, the solving strategy arrives at

$$
W_{3}-W_{2}=\left(m_{3}+m_{2}\right) a,
$$

which provides the acceleration of the bodies. This equation tells us that the difference between the weights is the force that causes acceleration $a$. This reading of the equation is the most common one.[1] Indeed, force has been thought of as the cause of acceleration. It will be argued that force $\mathrm{W}_{3}-\mathrm{W}_{2}$ is not causing that motion. 


\section{From the History of Science}

In 1854, Poggendorff, the editor of the famous journal Annalen der Physik und Chemie, showed experimentally that the weight of an Atm is reduced when it is brought into motion. This means, regarding our previous case, bodies 2 and 3 do not weigh $\mathrm{W}_{3}+\mathrm{W}_{2}$ when the machine moves. Figure 2 illustrates the Poggendorff apparatus. This consists of a lever, which has an Atm on one side and a counterweight on the other. If the Atm is prevented from moving, the lever is in equilibrium. When in motion, the lever inclines towards the counterweight side. The Atm became lighter.[2]

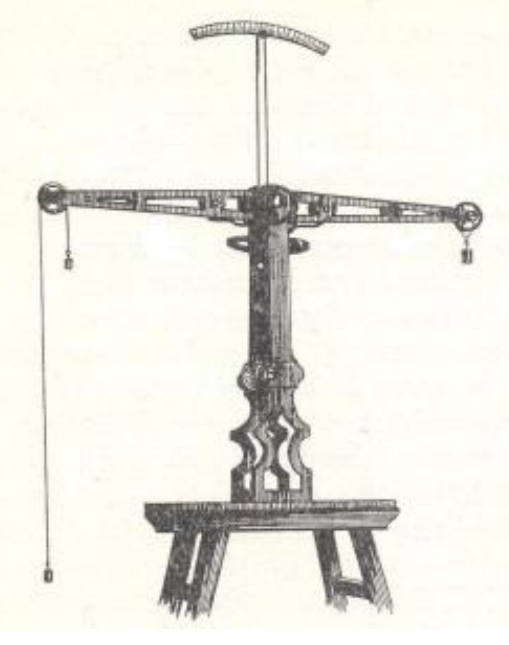

Figure 2: The Poggendorff apparatus.

Nowadays, this experiment can be easily carried out by using one of the widespread commercial measurement systems.[3] An Atm with the masses $0.2 \mathrm{~kg}$ and $0.05 \mathrm{~kg}$ was connected with a force sensor (fig. 3). When the machine was prevented from moving, the sensor was zeroed. When in motion, the weight read off was negative (fig. 4). The weight reduction was $0.86 \pm 0.03$ $\mathrm{N}$, which is close to the theoretical value: $0.89 \mathrm{~N}$.

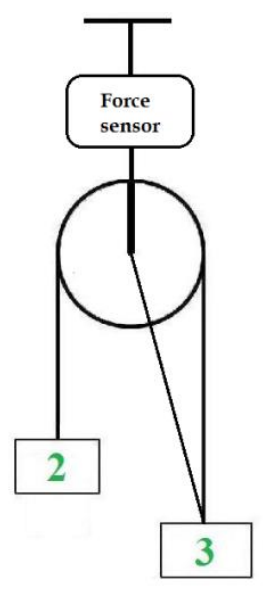

Figure 3: The thread, which prevents the machine from moving, is also represented. 


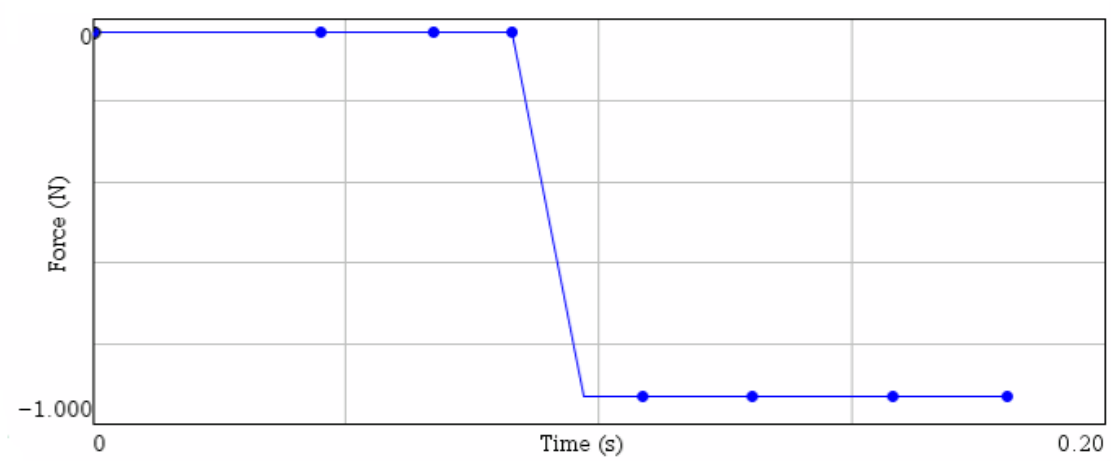

Figure 4: This graph shows a typical run of the experiment. The weight of an Atm decreases when in motion.

We will see next that not only the bodies taken together no longer weigh the same but also a weight difference equivalent to $\mathrm{W}_{3}-\mathrm{W}_{2}$ does not exist, when the machine moves. To achieve this goal, the weight of each body in motion must be determined. This requires a force sensor on each side, as represented in figure 5.[4]

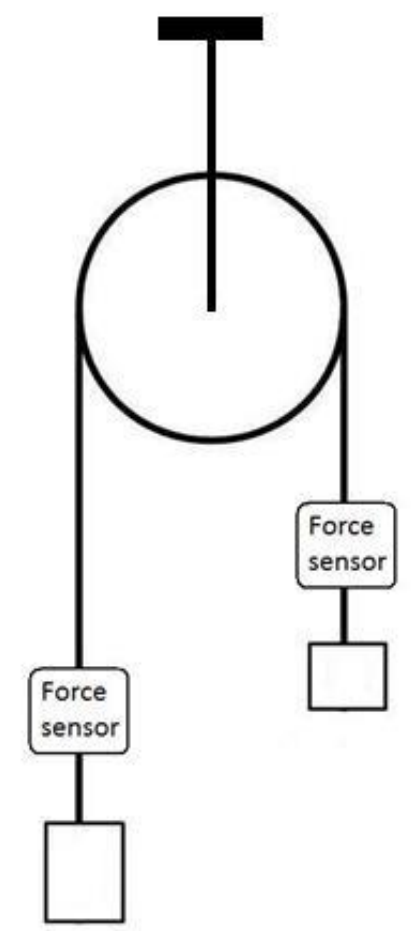

Figure 5: Schematic for measurement of the tensions.

The problem with this set up is that the sensor has a mass and this mass influences the motion of the machine. To overcome this obstacle, the sensors were inverted (fig. 6). 


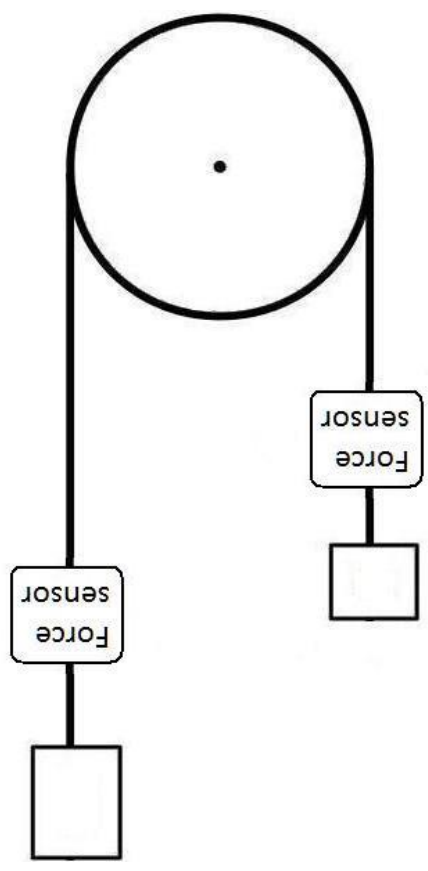

Figure 6: The inversion of the force sensors is decisive for the result that the tension is the same on both sides of an Atm.

Thus, each sensor measures the body suspended on it and its own weight, and there are no longer extra masses. The result is that the weight on each side of the machine is the same when this moves. The graph in figure 7 displays the result of a typical run of the experiment: the weights of the bodies as a function of time. In this instance, weights of $3.10 \pm 0.03 \mathrm{~N}$ and $1.57 \pm 0.03 \mathrm{~N}$ changed to $2.15 \pm 0.03 \mathrm{~N}$ and $2.07 \pm 0.03 \mathrm{~N}$ respectively, when in motion. These values are close to the theoretical one: $2.08 \mathrm{~N}$.

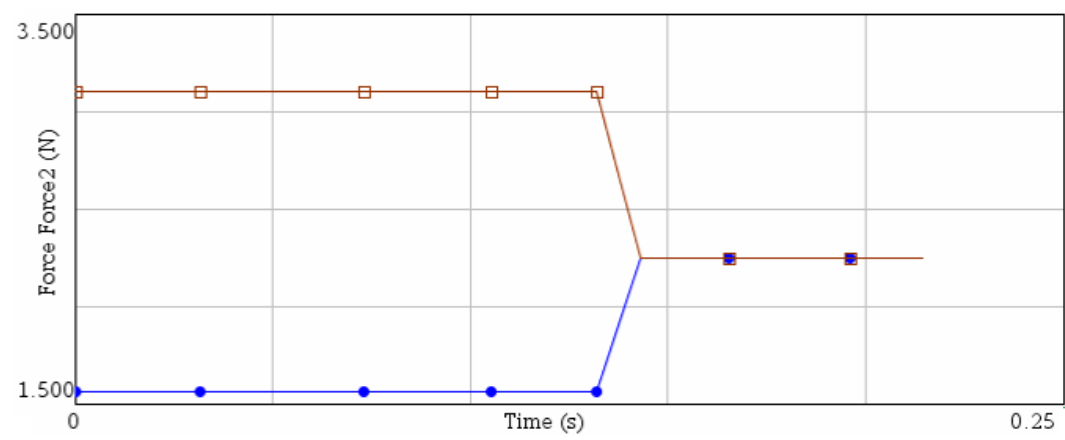

Figure 7: Weight reduction of the heavier suspended body and weight increase of the other. This image, displayed by the monitor connected to the force sensors, also shows that the weights of the bodies are practically equal to each other when the machine moves. (This set up can also be used to show experimentally the equality of the tensions on each side of an Atm. These experiments and others with Atwood machines will appear elsewhere.) 


\section{Conclusion}

When an Atwood machine moves, the weights of the bodies are not the initial weights. (It does not matter if we call them apparent weights or simply weights because this concerns only terminology.) Therefore, it does not make any sense to say that the initial weights cause the motion of the machine. We expect that the cause is acting and these weights cannot act because they do not exist when the machine moves.

From a logical point of view, this result shows that the most common definition of force force is the cause of acceleration - is not tenable. Indeed, it cannot be asserted that force is the cause of acceleration because there is one case in which what is taken as force cannot be the cause of that motion.

\section{References}

[1] R. L. Coelho, On the Concept of Force: How Understanding its History Can Improve Physics Teaching, Sc.Ed. 19 (2010) 91.

[2] J. C. Poggendorff, Über eine Abänderung der Fallmaschine, Ann. Phys. Che. 168 (1854) 179.

[3] P. Graneau, \& N. Graneau, In the Grip of the Distant Universe: The Science of Inertia, World Scientific Pub Co Inc, New Jersey 2006.

[4] R. L. Coelho, Could HPS Improve Problem-Solving? Sc.Ed. 22 (2013) 1058. 